\title{
SMART SHARING: SMART CITY PROJECT ON BICYCLE RENTAL FOR FOREIGN TOURISTS
}

\author{
Takao ITO ${ }^{1}$ and Mikiko Sode TANAKA ${ }^{2}$ \\ ${ }^{1}$ Kanazawa Institute of Technology, Japan \\ ${ }^{2}$ International College of Technology Kanazawa, Japan
}

\begin{abstract}
This paper reports the extra-curricular approach and successful results of the "Smart City" project at Kanazawa Institute of Technology and International College of Technology Kanazawa collaborating with the local government and communities in Japan. The curriculum and extracurricular projects are interwoven to develop students' innovation skills. Extracurricular activities play an important part to enhance the cross-disciplinary activities using the design process to solve problems. Students can perform activities over two or more years through extracurricular projects.

The "Smart City" project aims at proposing safe and secure city planning through development of IoT (Internet of Things) devices. The project members consist of students of the department of mechanical engineering, the department of electrical engineering, the department of information and computer science, etc. The project had the experience which designed the device to detect the dangerous place of the traffic accident using GPS (Global Positioning System). Taking advantage of the experience, they mounted the IoT device on a "Smart Sharing" bicycle which is composed of GPS, voice module and LPWAN (Low-Power Wide-Area Network). If the bicycle comes to a tourist spot, the tourist can hear sightseeing information in English. They also designed the tourist route by bicycle involving 15 tourist spots in Kanazawa City. To implement and test their solution, they planned and carried out the stamp rally in cooperation with "Machinori" which is the bike sharing service provided by Kanazawa City Government. The extra-curricular project shows an effect in acquisition of a special capability and basic ability to work in society.
\end{abstract}

Keywords: PBL, GPS, extracurricular design project, IoT, smart city

\section{INTRODUCTION}

The effectiveness of project-based learning and problem-based learning (both abbreviated to PBL) are widely accepted. PBL has been applied to various courses and has showed effectiveness in promoting learning outcomes or improving learning attitudes. PBL is one of key components to guarantee the quality of engineering design education through experience. Dewey has described "There is an intimate and necessary relation between the processes of actual experience and education" [1]. Kolb has expanded theoretically about learning and development in higher education and has asked for the consideration of social network as the institutional context and integrative development [2].

Based on these theories, Kanazawa Institute of Technology (KIT) applied PBL to its design and engineering programme as Project Design Programme to grow up independently minded, actively engaged engineers [3-4]. However, adequate project activities and meaningful experience are insufficient in curricular programmes because of restrictions of limited school hours or scholastic evaluation duties. For example, students need to learn the practical requirement analysis, the system diagram, and the architectural design to build an ICT system. They sometimes need to work in the field outside the university or on holidays. It is difficult to reflect these activities in syllabus or scores in a regular curriculum. So, KIT also focuses on the role of extracurricular activities [5]. They play important parts to enhance the cross-disciplinary activities using the design process to solve problems. The importance of extracurricular activities in education is recognized widely [6-7].

The social trend is consulted when considering extracurricular activities. Japan Ministry of Land, Infrastructure, Transport and Tourism (MILT) promotes the smart city public-private partnership platform. To realize Society 5.0, which is a high level of fusion of cyber and physical, MILT has 
positioned the smart city that utilizes new technologies and data such as AI (Artificial Intelligence) and IoT as a basic concept for town development [8]. Various smart city initiatives have begun in Japan.

As one of extracurricular activities of KIT, the "Smart City" project aims at proposing safe and secure city planning through development of IoT devices. The project collaborates with "Machinori Bicycle" which operates the bicycle rental in Kanazawa City of Japan. "Machinori Bicycle" provides the "Smart Sharing" service that tourists can rent and return bicycles at any of the 21 cycle ports around Kanazawa City [9]. There are several papers reported on bike sharing projects. Some of them focus on sustainable transportation design [10]. On the other hand, the "Smart City" project focuses on the design of IoT devices mounted on the sharing bikes.

The following parts of this paper are organized as follows: Section 2 will introduce the "Smart City" project activities and describe its collaboration with the local government. In Section 3, pedagogical effects of the project will be shown and discussed. Section 4 will conclude the paper.

\section{SMART CITY PROJECT AND ITS ACTIVITIES}

The "Smart City" project is one of extracurricular and cross-disciplinary activities of KIT. It started in 2016 when the project worked on developing the wristband mounted with GPS which detects and teaches the dangerous places where many traffic accidents occurred. The activity got the prize from Ministry of Internal Affairs and Communications Hokuriku Bureau of Telecommunications (MICHBTO) which promotes the usage of IoT and GPS. The project members consisted of students of the department of mechanical engineering, the department of electrical engineering, the department of information and computer science of KIT and students at International College of Technology Kanazawa (ICTK).

Taking advantage of the GPS handling experience, the members of 2018 proposed the smart sharing bicycle rental with GPS and got the prize from MICHBTO. They investigated the use situation of the bicycle rental in tourism. Tourism is concentrating on attraction of the tourist from overseas. However, they conceived that $95 \%$ of users are Japanese and that foreign users' percentage is low. They decided to design the IoT device which shows sightseeing information in English. An ordinary sightseeing guidance system uses a tourist's smart phone to show him or her the popular sightseeing routes and the scenic-spot information. However, using a smart phone during bicycle operation is forbidden in the viewpoint of traffic safety. So, they proposed the system which provides the voice guidance on the sightseeing information, route guidance, emergency evacuation information, and train operations to users by the IoT terminal attached to the bicycle instead of the mobile phone [11]. Acquiring approval of the bicycle rental company, Machinori, they continued developing the hardware which could be mounted on a bicycle.

They designed and implemented the IoT device on a bicycle which is composed of GPS, voice module and LPWAN. If a bicycle comes to a tourist spot, the tourist can hear sightseeing information in English. They also designed the tourist route by bicycle involving 15 tourist spots in Kanazawa City.

\subsection{The design of loT device on a bicycle}

Figure 1 shows the IoT device which is installed under the basket of a bicycle. This device is equipped with 8-bit CPU, GPS, MP3 voice module, speaker, micro SD card and LoRa (Long Range) module.

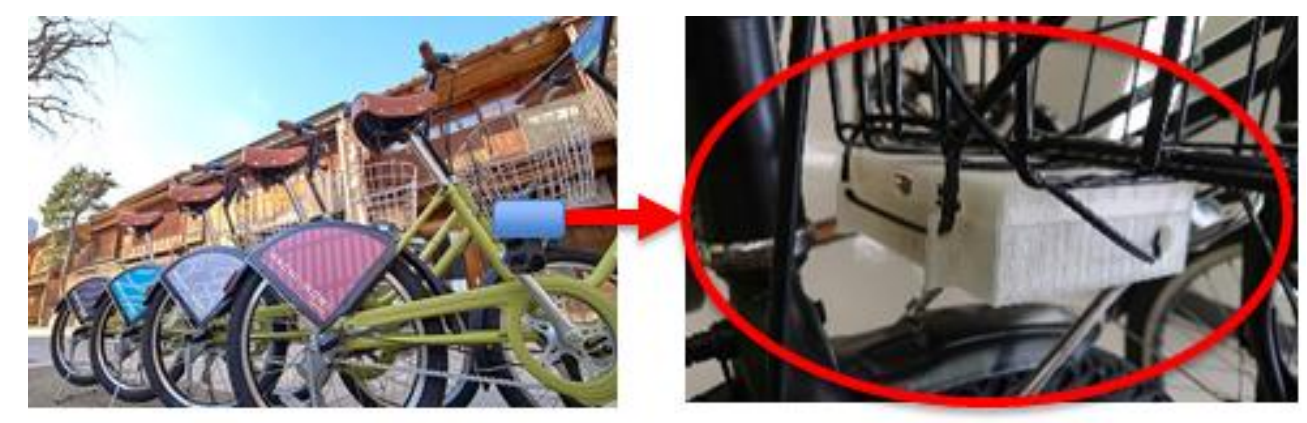

Figure 1. IoT device installed under the basket of a bicycle (Bicycle photos retrieved from Machinori [9] 
The configuration diagram of the device is shown in Figure 2. This device records the current location information from GPS on the micro SD card every two seconds. When the bicycle goes into the tourist site area set up beforehand, the sightseeing information voice is emitted from the voice module.

The location recording makes it possible to obtain tourism data such as which sightseeing spot the tourist has visited and how long they stayed there.

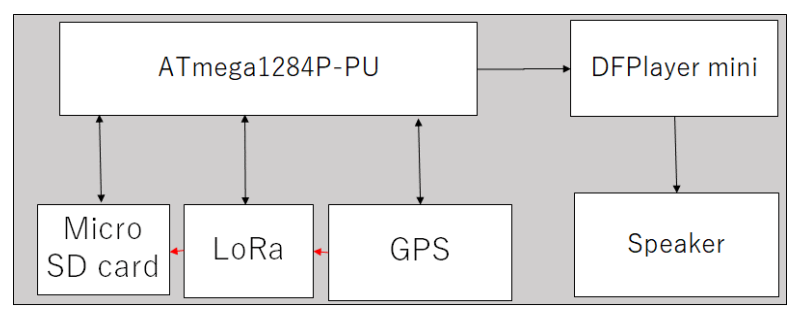

Figure 2. Configuration diagram of the loT device

\subsection{Setting the audio emitting range around the scenic spots}

To program so that the sightseeing information voice is emitted when the bicycle approaches the scenic spots, it is important to define the range of the scenic area where the IoT device emits the voice information. Assuming the speed of the sightseeing bicycle is $15 \mathrm{~km} / \mathrm{h}$, five playback ranges were examined from $20 \mathrm{~m}$ to $100 \mathrm{~m}$. When the range is small, the bicycle may pass through the area before the information is emitted. On the other hand, if an area is large, interference between the neighbouring areas occurs and it is hard to distinguish from the next tourist site. From trial and error experiments, the emitting range was set to $40 \mathrm{~m}$.

15 check points where the information voice is emitted are set around Kanazawa City centre area as shown in Figure 3. The program was also implemented which prevents reproducing the same information repeatedly once the bicycle entered the sightseeing area and the information was emitted.

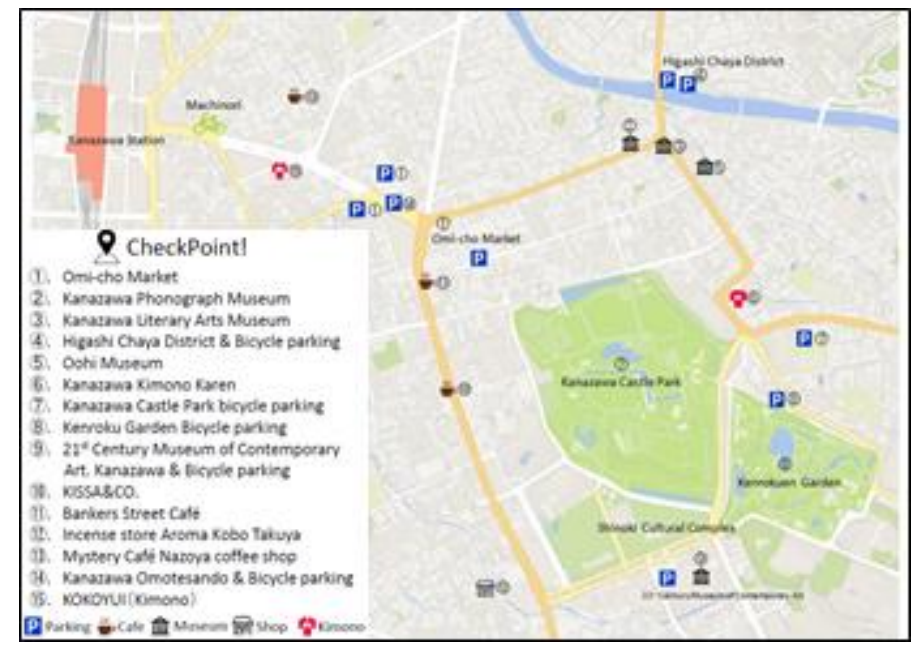

Figure 3. Check points around Kanazawa City

\subsection{Stamp rally}

In October 2019, the project planned and performed the stamp rally on bicycles for foreign tourists as one of the events of Overseas Challenge Programme for Students. Tourists could use the bicycle rental with the IoT device free and got some souvenir items if they collected more than four stamps out of 15 check points. The event was supported by the University Consortium Ishikawa and the Ishikawa Prefecture Government.

The location recording data obtained from five tourists are shown in Figure 4. The left figure shows the locus which the tourists passed. The right figure shows the reproduction place of the audio assist. These data will be useful to find how and where tourists move around in sightseeing. The tourists also gave some comments: "Vocal sound cannot be heard in the place where the surroundings are noisy, however it is somewhat shameful that vocal sound becomes a loud sound." 
It was the precious experience for the students which could not be obtained in a class.

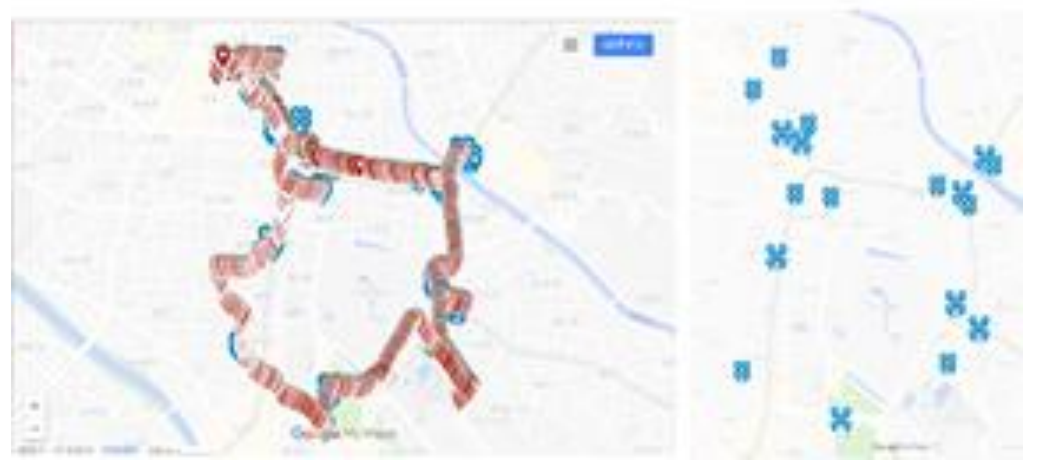

Figure 4. The location recording data

\section{Pedagogical efFects}

\subsection{Evaluation by questionnaire}

It is hard to analyse pedagogical effects of extra-curricular projects because they include a variety of skills which are difficult to measure by test scores. No paper examination is done to measure the learning knowledge during the project.

Therefore, questionnaire-based evaluation was carried out to measure pedagogical effects on students' growth. Questionnaires are designed to evaluate students' self-confidence on the improvement of the fifteen skills which will be required for an engineer. Questionnaires include four free descriptions: their expectations for the project, the difficulties during the project, the growth by the project and the usefulness of the project. They are listed on Table 1.

Table 1. Questionnaires

\begin{tabular}{|c|c|c|}
\hline No. & Questions & Question type \\
\hline 1 & Presentation skills & \multirow{15}{*}{$\begin{array}{c}5 \text { level score } \\
\text { 5: greatly improved } \\
\text { 3: neutral } \\
\text { 1: greatly fell }\end{array}$} \\
\hline 2 & Report writing skills & \\
\hline 3 & Team activity commitment & \\
\hline 4 & Communication skills & \\
\hline 5 & Planning skills & \\
\hline 6 & Leadership & \\
\hline 7 & Ethics & \\
\hline 8 & Information gathering & \\
\hline 9 & Patent research & \\
\hline 10 & Mechanical design skills & \\
\hline 11 & Circuit design skills & \\
\hline 12 & Programming skills & \\
\hline 13 & System evaluation skills & \\
\hline 14 & Logical Thinking & \\
\hline 15 & Knowledge on major & \\
\hline $\mathrm{a}$ & What did you expect on the project? & \multirow{4}{*}{ Free description } \\
\hline $\mathrm{b}$ & What was the most difficult thing during the project? & \\
\hline $\mathrm{c}$ & What skill do you think most improved? & \\
\hline $\mathrm{d}$ & What do you think this project will be useful? & \\
\hline
\end{tabular}

\subsection{Results and discussion}

Eleven actively engaged students answered the questionnaires. They are a senior of mechanical engineering, sophomores of electrical engineering and freshmen of mechanical engineering, robotics 
and media informatics. The self-scoring results are shown in Figure 5. Team activity, Communication, Programming and Logical thinking show meaningful improvement in average: score $>3.5$ at $95 \%$ confidence interval. These skills are important to work as an engineer. As the senior student took the role of presentation and reporting, the other students did not have a good chance to improve presentation skills or reporting skills. There was no patent review assignment during the project. Sophomores of the department of electrical engineering scored high in major knowledge improvement, while students of other departments did not feel the improvement of knowledge on major.

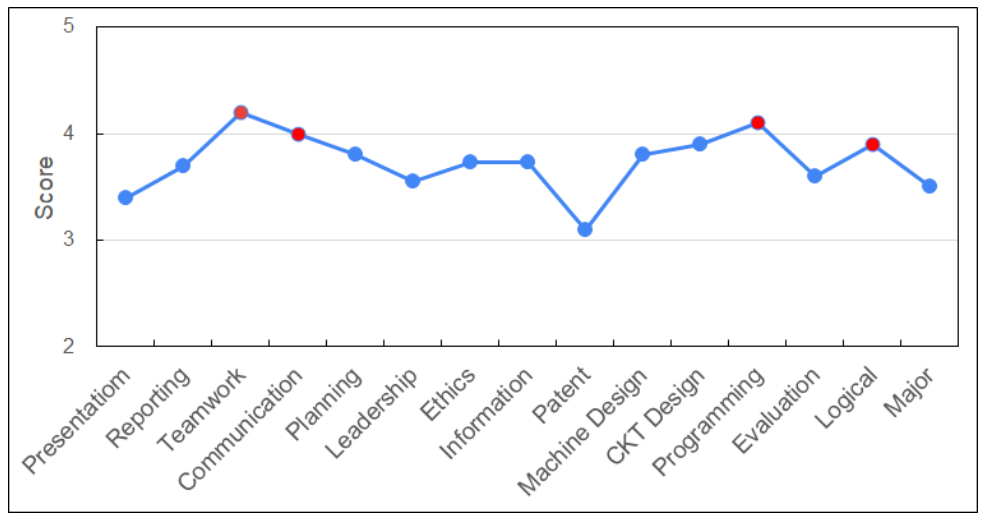

Figure 5. Questionnaire results

About the expectation for the project of the free description reply, the senior answered, "I wanted to know whether our sightseeing guidance system is useful for a tourist" while the sophomore answered, "I wanted to perform practical electronic device development through the design and manufacture of equipment."

Answering the improving skills, the senior pointed the project management and scheduling as the leader which may be hardly obtained through curricular courses. Sophomores answered circuit design skills which complements curricular courses. They also answered that challenging spirits improved.

To the question of how the project will be useful, a sophomore answered, "I can investigate by myself and overcome difficulties even after graduation."

Text mining of free description answers shows the word linkage between "project" and "growth", "knowledge" and "programming", and "communication ability". That means the usefulness of the project to growth of programming knowledge and communication.

\section{CONCLUSIONS}

The "Smart City" project, the extracurricular and cross disciplinary IoT activity of KIT and ICTK collaborating with the local government and communities, is shown. Students took the lead and performed the project. Teachers' role is support and technical advisers. Unintentionally, the project was progressed according to the CDIO approach [12]. They conceived the problems on the bicycle rental for foreign tourists, designed the IoT device which could be implemented under the basket of the bicycle rental and operated the stamp rally to verify the usefulness of the device.

The pedagogical effectiveness of PBL through the extracurricular project is confirmed by questionnaires. Four basic skills as an engineer improved by the project activities: Team activity, Communication, Programming and Logical thinking. Through the interdisciplinary and multi grade project activities, students could acquire more practical knowledge which could not be experienced in curricular programmes: the senior students acquired the project management and scheduling skills, sophomores acquired circuit design and programming skills with communication skills. This project shows the importance of extracurricular activities in education.

\section{ACKNOWLEDGEMENTS}

The research was supported by the University Consortium Ishikawa, the Ishikawa Prefectural Government, Machinori, and JSPS KAKENHI Grant-in-Aid for Scientific Research (C) 19K03094. 


\section{REFERENCES}

[1] Dewey, J. Experience and education, 1997 (Simon \& Schuster, New York).

[2] Kolb, D.A. Experiential Learning: Experience as the source of learning and development, 1984 (PTR Prentice Hall, New Jersey).

[3] Ito T., Shin M., Miyazaki K., Iwata S. and Sentoku E. The Effects of Spiral Educational Method through PBL: KIT Project Design Programme, Proc. of the 43rd Annual SEFI Conference, 2015.

[4] Nguyen, H., Sato, K., Dam-Duy, L. and Nguyen, V. The Educational Influences of Project Design Education on Students' Learning Abilities (The First Report), Proc. of the 14th International CDIO Conference, Kanazawa, Japan, June 2018.

[5] Ito T., Shin M., Miyazaki K., Iwata S. and Sentoku E. The Project Design Education Collaborating with City Governments and Communities, Proc. of the 18th International Conference on Engineering \& Product Design Education, 2016.

[6] Gonzalez, A. and Millunchick, J. M. Extracurricular Engineering Activities and College Success. In ASEE's 123rd Annual Conference \& Exposition. New Orleans, June 2016.

[7] Dukart, K. Creating Meaningful Experiences Through Extracurricular Project-Based Experiential Learning. In 2017 ASEE Annual Conference \& Exposition. Columbus, June 2017.

[8] MILT, smart city public-private partnership platform, Accessed 24 December 2019. Retrieved from http://www.mlit.go.jp/scpf/index.html

[9] Machinori, Service Information Guide, Accessed 24 December 2019. Retrieved from https://www.machi-nori.jp/en/

[10] Nikitas, A., Wallgren, P., \& Rahe, U. Public bicycles: How the concept of human-oriented "mobility sharing" technology can influence travel behaviour norms and reshape design education, Proc. of the 16th International Conference on Engineering \& Product Design Education, 2014, pp. 159-165.

[11] Yumeto Kojima, Kouki Hayashi, Kenta Akamatu, Kyouiti Hasegawa and Mikiko Sode Tanaka $A$ Study of Rental Cycle System using Location Information and Contribution to City Planning, IEEE 1st Global Conference on Life Sciences and Technologies (LifeTech 2019), March 2019. CDIO, About CDIO, Accessed 27 April 2020. Retrieved from http://www.cdio.org/about. 